\title{
RITA requires elF2a-dependent modulation of mRNA translation for its anti-cancer activity
}

\author{
Johannes Ristau', Vincent van Hoef ${ }^{1}$, Sylvain Peuget $\mathbb{C}^{2}$, Jiawei Zhu², Bo-Jhih Guan ${ }^{3}$, Shuo Liang ${ }^{1}$, Maria Hatzoglou', \\ Ivan Topisirovic (10), Galina Selivanova ${ }^{2}$ and Ola Larsson (1) ${ }^{1}$
}

\begin{abstract}
Tumor protein 53 (p53, encoded by the TP53 gene) is a key tumor suppressor regulating cell fates in response to internal and external stresses. As TP53 is mutated or silenced in a majority of tumors, reactivation of p53 by small molecules represents a promising strategy in cancer therapeutics. One such agent is RITA (reactivation of p53 and induction of tumor cell apoptosis), which restores p53 expression in cells with hyperactive HDM2 and induces apoptosis. Yet, mechanisms underlying the anticancer activity of RITA are incompletely understood. Here we show that RITA suppresses mRNA translation independently of p53 by inducing elF2a phosphorylation. Surprisingly, reactivation of p53 following RITA treatment is critically dependent on elF2a phosphorylation. Moreover, inhibition of elF2a phosphorylation attenuates pro-apoptotic and anti-neoplastic effects of RITA, while inducing phosphorylation of elF2a enhances the anticancer activity of RITA. Collectively, these findings demonstrate that the translational machinery plays a major role in determining the antineoplastic activity of RITA, and suggest that combining p53 activators and translation modulators may be beneficial.
\end{abstract}

\section{Introduction}

Multiple stress signals, including DNA damage and oncogenic signaling, converge to increase the level and activity of p53 which in turn orchestrates gene expression programs to determine cell fate decisions and suppress neoplastic transitions ${ }^{1,2}$. It is thus generally thought that cells restrict p53 activity to progress towards malignancy ${ }^{3,4}$. Consistently, a pan-cancer study identified TP53 as the single most mutated gene ${ }^{5}$. Moreover, in tumors with wildtype TP53, expression of the p53 protein is commonly repressed via overexpression of HDM2 or HDMX which target $\mathrm{p} 53$ for proteasomal degradation ${ }^{6,7}$. Reactivation of p53 therefore holds significant therapeutic promise, but it is necessary to consider the variety of mechanisms which

Correspondence: Ola Larsson (Ola.Larsson@ki.se)

'Department of Onkology-Pathology, Science for Life Laboratories, Karolinska Institutet, Stockholm, Sweden

${ }^{2}$ Department of Microbiology, Tumor and Cell Biology, Karolinska Institutet, Stockholm, Sweden

Full list of author information is available at the end of the article. These authors contributed equally: Johannes Ristau, Vincent van Hoef Edited by P. Bouillet inactivate normal p53 function in neoplasia when devising such approaches ${ }^{8}$. To this end, a range of small molecules have been identified including those refolding mutant p53 (e.g. PRIMA- ${ }^{9}$ ) or inhibiting proteasome dependent degradation of wild-type p53 (e.g., Reactivation of p53 and Induction of Tumor Apoptosis [RITA $]^{10}$, Nutlin-3a ${ }^{11}$, SAR405838 ${ }^{12}$ ). Although clinical trials using p53 activators have been conducted ${ }^{13}$ or are still ongoing (NCT01143519, NCT01636479), the downstream mechanisms which mediate the effects of these drugs on, e.g., apoptosis and/or cell cycle upon p53 reactivation are incompletely understood. Perplexingly, these agents do sometimes not solely rely on restoring p53 transactivation ${ }^{14-16}$ and, in some cases, anticancer effects are observed independently of TP $53^{17}$. This suggests that reactivation of p53 function acts in concert with other mechanisms and/or that reactivation of p53 may be a secondary effect of drug action. Indeed, several mechanisms have been proposed to explain TP53independent induction of cell death following treatment with p53 reactivating drugs including DNA damage ${ }^{18}$, endoplasmic reticulum (ER) stress $^{19}$ and an imbalance in

\section{(c) The Author(s) 2019}

(c) OPen Access This article is licensed under a Creative Commons Attribution 4.0 International License, which permits use, sharing, adaptation, distribution and reproduction cc) in any medium or format, as long as you give appropriate credit to the original author(s) and the source, provide a link to the Creative Commons license, and indicate if changes were made. The images or other third party material in this article are included in the article's Creative Commons license, unless indicated otherwise in a credit line to the material. If material is not included in the article's Creative Commons license and your intended use is not permitted by statutory regulation or exceeds the permitted use, you will need to obtain permission directly from the copyright holder. To view a copy of this license, visit http://creativecommons.org/licenses/by/4.0/. 
glutathione (GSH) vs. reactive oxygen species (ROS) production $^{15}$. These studies suggest that characterization of downstream mechanisms of p53 reactivation agents may allow for rational selection of patients for treatment and/or improve design of drug combinations encompassing p53 activators.

Multiple cellular stresses activate the integrated stress response (ISR) to globally suppress protein synthesis (reviewed in ref. ${ }^{20}$ ). This is chiefly achieved via the phosphorylation $^{21}$ of the alpha subunit of the eukaryotic translation initiation factor 2 (eIF2 $\alpha$ ) which delivers initiator tRNA during translation initiation in a ternary complex (TC) with GTP ${ }^{21}$. Upon initiator tRNA delivery, eIF2-GTP is hydrolyzed to GDP and subsequently recycled by eIF2B which acts as a guanine nucleotide exchange factor (GEF) for the next round of initiation ${ }^{21}$. eIF2 $\alpha$ phosphorylation (reviewed in ref. ${ }^{22}$ ), by one of four stress sensing kinases (PKR-like endoplasmic reticulum kinase [PERK], Heme-regulated inhibitor [HRI], general control nonderepressible-2 [GCN2] or Protein Kinase RNA-activated $[\mathrm{PKR}]^{23-26}$ ) inhibits the GEF activity of eIF2B thereby preventing TC recycling. This leads to suppression of global protein synthesis, which co-occurs with translational activation of a subset of mRNAs, with specific features in their $5^{\prime}$ un-translated regions (UTR) including inhibitory upstream open reading frames (uORFs), which encode stress-induced factors including activating transcription factor 4 (ATF4) and C/EBP homologous protein (CHOP). If the stress is resolved, eIF2 $\alpha$ is dephosphorylated by the GADD34:PP1 complex $^{27}$, and protein synthesis recovers (reviewed in ref. ${ }^{22}$ ). This recovery also involves translational reprogramming that allows translation of mRNAs that support stress resolution ${ }^{28}$. Unresolved stress, however, often results in cell death which is mediated by factors such as CHOP and binding immunoglobulin protein (BIP) $)^{29}$.

RITA was discovered in a small molecule screen designed to identify compounds restoring wild-type p53 activity and is thought to inhibit the interaction between p53 and HDM $2^{10}$. Further studies suggested that RITA induces apoptosis independent of $\mathrm{p} 53^{16,17,30}$. Here we show that RITA induces apoptosis and represses mRNA translation by inducing eIF $2 \alpha$ phosphorylation independent of p53; and, surprisingly, that reactivation of p53 following RITA treatment requires eIF2 $\alpha$ phosphorylation. Moreover, modulation of eIF2 $\alpha$ phosphorylation largely accounts for the antineoplastic effects of RITA in cell culture. Thus, modulation of mRNA translation appears to be required for the anti-tumor effects of RITA.

\section{Materials and methods \\ Cell lines and reagents}

MCF7 (WT, TP53+/+, TP53-/-, sh-control, sh4EBP1, MCF7 TP53-/- shD133/D160p53), GP5D and HT1080 cells were maintained in Dulbecco's Modified Eagle Medium (Gibco Thermo Fisher, Gothenburg, Sweden) with 1\% Penicillin-Streptomycin (Thermo Fisher), 1\% GlutaMAX (Thermo Fisher) and 10\% Fetal Bovine Serum (Thermo Fisher). HCT116 TP53+/+ cells were maintained in McCoy's $5 \mathrm{~A}$ (Modified) Medium (Thermo Fisher) with $1 \%$ Penicillin-Streptomycin and 10\% Fetal Bovine Serum. MCF7 TP53+/+ and MCF7 TP53-/cells were generated by CRISPR/Cas9 mediated TP53 deletion (TGAAGCTCCCAGAATGCCAG) as described $^{31}$. Briefly, stable Cas9 expressing MCF7 were established and then transfected two times with TP53 sgRNA targeting exon 4. Cell lines were obtained as follows: MCF7 WT cells were purchased from Sigma Aldrich (Schnelldorf, Germany). MCF7 sh4EBP1, HT1080 WT, HT1080 S51A were received from Ivan Topisirovic; HCT116 TP53+/+ and GP5d cells were received from Galina Selivanova. Cells were cultured to a maximum of 15 passages ( $<2$ months) after thawing and all experiments where performed during this period. Mycoplasma testing was performed by PCR [primers: GGCG AATGGGTGAGTAACACG (forward) and CGGATA ACGCTTGCGACTATG (reversed); samples were compared to a positive and negative control] after at least 2 days after thawing and monthly. RITA (2443/1) and GSK2606414 (5107) were purchased from Tocris (Bristol, United Kingdom). Integrated stress response inhibitor (ISRIB; SML0843), N-actetyl cystein NAC (A9165) and salubrinal (SML0951) were purchased from SigmaAldrich.

\section{Polysome-profiling}

Cells were seeded in $15 \mathrm{~cm}$ culture dishes and harvested at $\sim 75 \%$ confluence. Following treatment, cytosolic and polysome-associated RNA were extracted as described previously $^{32}$. After sedimentation of the cytosolic lysate in the sucrose gradient, absorbance at $254 \mathrm{~nm}$ was recorded along the gradient, resulting in polysome-tracings. Overlays of tracings were normalized for input material and quantification was performed by measuring the area under the curve for efficiently translated mRNA (herein defined as association with $>3$ ribosomes).

\section{${ }^{[35]}$ S-methionine/cysteine labeling}

${ }^{[35]}$ S-labeled methionine and ${ }^{[35]}$ S-labeled cysteine incorporation in nascent proteins was measured according to the manufacturer's instruction (EasyTag EXPRESS ${ }^{35} \mathrm{~S}$ Protein Labeling Mix, Perkin Elmer, Upplands Väsby, Sweden). Briefly, $10^{5}$ cells were seeded per well in six well plates, allowed to attach overnight and treated in methionine and cysteine free DMEM (Gibco Thermo Fisher) with RITA in presence or absence of ISRIB at indicated concentrations for $4 \mathrm{~h}$. Next, cells were incubated for $30 \mathrm{~min}$ in DMEM supplemented with S35 labeled Met and Cys $(20 \mu \mathrm{Ci} / \mathrm{ml})$, after 
which they were washed three times with PBS and lysed with $100 \mu \mathrm{l}$ radio-immunoprecipitation assay buffer (RIPA buffer; $100 \mathrm{mM}$ sodium chloride, $1.0 \%$ Triton X-100, $0.5 \%$ sodium deoxycholate, $0.1 \%$ SDS, $50 \mathrm{mM}$ Tris $\mathrm{pH} 8.0$ [SigmaAldrich]). The lysate was centrifuged for $10 \mathrm{~min}$ at $20.000 \mathrm{rpm}$ in a tabletop centrifuge and $15 \mu \mathrm{l}$ of the supernatant was spotted on a glass fiber filtermat (Filtermat B, Perkin-Elmer). The filtermat was subsequently washed twice in 10\% Trichloroacetic acid (TCA) and once with ethanol: acetone (50:50) for 10 min each and dried overnight. A melton scintillator (MeltiLex, Perkin-Elmer) was applied to the filtermat and counts per minute were monitored using a microBeta plate reader (MicroBeta2, Perkin Elmer).

\section{ROS detection using CellROX}

Endogenous ROS levels were detected using the CellROX Deep Red Reagent (C10422, ThermoFisher Scientific). MCF7 cells were grown to 70\% confluency prior to $16 \mathrm{~h}$ incubation with $5 \mu \mathrm{M} \mathrm{N}$-acetyl cysteine with or without $1 \mu \mathrm{M}$ RITA added during the last $4 \mathrm{~h}$. After this, the Deep Red reagent was added to the culture medium for $30 \mathrm{~min}$ at a final concentration of $5 \mu \mathrm{M}$ after which the cells were washed three times with PBS and analyzed by FACS. Normalization to the control condition and plotting was done using FCS Express 6 Plus Research Edition (DE Novo Software, Glendale, CA, USA).

\section{ROS detection using DCFDA}

One million cells were seeded in $6 \mathrm{~cm}$ dishes. The day after, cells were treated as indicated, then washed with PBS and incubated $30 \mathrm{~min}$ with $10 \mu \mathrm{M}$ DCFDA (ThermoFisher Scientific) in serum free medium. Cells were then trypsinized, washed twice with PBS and fluorescence was analyzed by a FACSCalibur flow cytometer (BD Biosciences, Stockholm, Sweden) using CellQuest Pro software (BD Biosciences).

\section{Western blotting}

Whole cell lysates were extracted using RIPA buffer supplemented with phosphatase and protease inhibitors (Roche PhosSTOP and cOmplete tablets). $20 \mu \mathrm{g}$ of protein was subjected to SDS-PAGE using $10 \%$ or $13 \%$ BisAcrylamide gels (29:1) (Sigma-Aldrich) before transfer to a $0.2 \mu \mathrm{m}$ nitrocellulose membrane (BioRad, Solna, Sweden). All antibodies were used in $4 \%$ Bovin serum albumin dissolved in TBS-buffer $(20 \mathrm{mM}$ Tris, $150 \mathrm{mM} \mathrm{NaCl})$ and $0.1 \%$ Tween 20. Primary antibodies used in this study, were incubated under constant agitation at $4{ }^{\circ} \mathrm{C}$ for $16 \mathrm{~h}$ : P53, DO-1, Santa Cruz Biotechnology (Heidelberg, Germany), 1:800; beta-actin, Sigma-Aldrich, 1:10,000; PARP (46D11), Cell Signaling Technologies 9532 S, 1:1000; phospho-4EBP1 (S65), Cell Signaling Technologies (purchased via BioNordika Sweden, Stockholm, Sweden), 9456 S, 1:1000; 4EBP1, Cell Signaling Technologies,
9452S, 1:1000; phoshpo-S6K (Thr389), Cell Signaling Technologies, 9234S, 1:1000; total S6K, Cell Signaling Technologies, 9202S, 1:1000; phospho-eIF2 $\alpha$ (S51), Cell Signaling Technologies, 9721S, 1:1000; eIF2 $\alpha$, Cell Signaling Technologies, 9722S, 1:1000.

Secondary antibodies used in this study were incubated under constant agitation at RT for 30 min: goat antirabbit, BioRad, 19205 S, 1:10,000; goat anti-mouse, Merck Millipore (Schnelldorf, Germany), AP127P, 1:10000. To re-probe membranes with additional antibodies, stripping was performed using Restore Western Blot Stripping Buffer (Thermo Fisher Scientific) for $15 \mathrm{~min}$ at RT and subsequent blocked using 4\% BSA in TBS-T for $30 \mathrm{~min}$. Before exposure, and between incubations of primary and secondary antibodies, membranes were washed three times with TBS-T. Proteins were visualized using Clarity Western ECL Substrate (BioRad) on a Thermo Fisher iBright CL1000 system.

\section{Lentiviral transduction of the D133/D160p53 shRNA construct}

HEK293T cells were transfected with pCMV-VSVG, pMDLg-RRE, pRSV-REV and a transfer vector with an shRNA (5'-GACTCCAGTGGTAATCTAC-3') targeting exon 7 of TP53 (D133/D160p53 shRNA) using a Calcium Phosphate Transfection Kit (CAPH05-1KT, Sigma Aldrich). The supernatant was collected $48 \mathrm{~h}$ after transfection and filtered $(0.45 \mu \mathrm{m})$. MCF7 TP53-/- were then transduced using $8 \mu \mathrm{g} / \mathrm{mL}$ polybrene and media was changed after $16 \mathrm{~h}$. This generated MCF-7 TP53-/shD133/D160p53 cells.

\section{Reverse transcription and qPCR}

400.000 MCF-7 TP53-/-shD133/D160p53 cells were seeded per well in a 6-well plate and treated with $1 \mu \mathrm{M}$ RITA the following day. RNA was extracted using Aurum total RNA mini Kit (7326820, BioRad). $1 \mu \mathrm{g}$ of total RNA was used for reverse transcription using iscript cDNA synthesis kit (1708891, BioRad) according to manufacturer's instructions. qPCR was performed using the Premix Ex Taq Kit (RR390W, Takara, Gothenburg, Sweden) using the following protocol: $95^{\circ} \mathrm{C}, 30 \mathrm{~s}$ for one cycle followed by 40 cycles of $95^{\circ} \mathrm{C}, 5 \mathrm{~s} ; 60^{\circ} \mathrm{C}, 30 \mathrm{~s}$. The following primers were used: Beta actin: fwd. 5'TTCTA CAATGAGCTGCGTGTG3', rev. 5'GGGTGTTGAAGG TCTCAAA amplification efficiency 2.05; D133/D160p53 fwd: GTGCAGCTGTGGGTTGATTC, rev: ACCATCG CTATCTGAGCAGC, amplification efficiency 2.11. Ct values were normalized to actin and expression was calculated using the $\Delta \Delta \mathrm{Ct}$-method.

Flow cytometry and Annexin V-propidium iodide staining Adherent and floating cells were collected by centrifugation $(1200 \times g$ for $5 \mathrm{~min}$ in a tabletop centrifuge) 
and stained using the Dead Cell Apoptosis with FITC AnnexinV/PI kit according to manufacturer's instructions (Life technologies Thermo Fisher, V13242). Fluoresence was analyzed using an ACEA NovoCyte flow cytometer (ACEAbio, AH diagnostics, Aarhus, Denmark), and further normalized to cell counts using FCS Express 6.

\section{Colony formation assay}

Colony formation was assessed by seeding 1000 MCF7 cells per well in a 6-well plate (Corning). After $16 \mathrm{~h}$, cells were treated with the indicated compounds for $4 \mathrm{~h}$. Media was changed every three days. After 10 days, colonies were stained with Crystal Violet staining solution [0.4\% Crystal violet (Sigma-Aldrich), 6\% Glutaraldehyde (Sigma-Aldrich) in $\mathrm{H} 2 \mathrm{O}$ ] for $30 \mathrm{~min}$ on an orbital shaker (20 rpm) and destained with $\mathrm{ddH} 2 \mathrm{O}$. Quantification was performed using OpenCFU (http://opencfu.sourceforge.net/) with the following parameters: Threshold: regular $=5$, Radius $=5$, Auto $=$ max. Data was normalized to a DMSO control and the experiment was performed three times where each experiment included a technical duplicate.

\section{Statistical analysis}

Experiments were performed at least three times $(n=3)$ unless otherwise stated in the figure legend. All replicates were biological. Statistics were calculated using two-sided unpaired Student's $t$-tests in which equal variance was assumed ( $\mathrm{R}$ studio Version 3.4.3) using a minimum of three biological replicates unless otherwise indicated.

\section{Results}

\section{RITA induces PARP cleavage and represses mRNA} translation in a TP53-independent manner

As previously described, $8 \mathrm{~h}$ treatment of MCF7 cells with $1 \mu \mathrm{M}$ RITA results in a strong p53 accumulation and cleavage of the apoptosis marker PARP (Fig. S1). Perturbations in translation have been linked to both changes in p53 activity and cell death ${ }^{33,34}$. We therefore explored the effects of RITA on protein synthesis using the polysome profiling technique, which separates mRNAs according to the number of associated ribosomes ${ }^{32}$ (Fig. 1a). This allows for visualization and quantification of ribosomes engaged in efficient translation (herein defined as those mRNAs associated with $>3$ ribosomes) which reflects global translation levels (Fig. 1a). Polysome-profiling analysis revealed that RITA reduces the number of ribosomes engaged in efficient translation with a concomitant increase in $80 \mathrm{~S}$ monosomes (Fig. 1b, c). Although the effects of RITA were firstly attributed to p53 activation, a recent study revealed that RITA may exert p53independent effects ${ }^{16,17}$. To assess whether effects of RITA on mRNA translation require p53 we employed MCF7 cells wherein TP53 was silenced using CRIPSRCas9 technology. Strikingly, RITA had a similar effect on
PARP cleavage (Fig. 1d) and global translation levels, assessed by polysome profiling, in MCF7 TP53-/- as compared to MCF7 TP53+/+ cells (Fig. 1e). To further quantify RITA's effects on global translational in the context of $\mathrm{p} 53$, we measured incorporation of ${ }^{[35]} \mathrm{S}$ methionine and ${ }^{[35]}$ S-cysteine in nascent proteins following RITA treatment. This confirmed a comparable reduction of protein synthesis in TP53+/+ and TP53-/MCF7 cells upon RITA treatment (Fig. 1f). Thus, RITA induces PARP cleavage and suppresses global translational efficiency independent of TP53.

\section{RITA suppresses translation independently of ROS and the mTOR/4E-BP axis}

The pro-apoptotic effects of RITA were previously reported to be potentiated by accumulation of $\operatorname{ROS}^{35}$. Moreover, recent reports indicate that other p53 reactivating drugs such as PRIMA-1Met may exert TP53independent effects on apoptosis by altering GSH/ROS production $^{15}$. Because oxidative stress can suppress protein synthesis ${ }^{36}$, we assessed whether RITA-induced oxidative stress explains its suppressive effect on mRNA translation. As described previously ${ }^{35}, 8 \mathrm{~h}$ treatment of MCF7 cells with $1 \mu \mathrm{M}$ RITA resulted in an elevation of ROS as measured by staining with CellROX Deep Red dye (Fig. 2a). Although RITA-induced ROS accumulation could be completely reversed using the anti-oxidant $\mathrm{N}$ Acetyl Cysteine (NAC; Fig. 2a), PARP cleavage persisted (Fig. 2b), p53 levels were elevated (Fig. 2b) and mRNA translation was decreased (Fig. 2c). Thus, RITAassociated accumulation of ROS does not explain its effects on mRNA translation.

The mTOR pathway is a major regulator of protein synthesis and integrates multiple internal and external cues such as nutrient, oxygen, energy and growth factor availability $^{37}$. A key link between mTOR and mRNA translation is mediated by its phosphorylation and inactivation of the small translation-inhibitory 4E-binding proteins (4E-BPs). 4E-BPs bind to the $5^{\prime}$ cap-binding protein eIF4E and prevent assembly of the eIF4F complex $^{22,38}$. Therefore, to investigate the role of the mTOR/ 4E-BP axis in mediating the effects of RITA on mRNA translation, we used MCF7 cells where 4E-BP1 expression was silenced using a short hairpin RNA (sh4EBP1; Fig. 2d) and assessed the effect of RITA $(1 \mu \mathrm{M}$ for $8 \mathrm{~h})$ on mRNA translation. As assessed by polysome-tracings, cells lacking 4E-BP1 showed a similar reduction in the proportion of ribosomes engaged in efficient translation as compared to control cells (Fig. 2e, f). Moreover, in contrast to treatment with the active site mTOR inhibitor torin $1^{39}$, following RITA treatment we observed no change in phosphorylation of 4E-BP1 or S6K which are downstream targets of mTOR (Fig. 2g). Thus, RITA modulates translation independently of the mTOR/4E-BP axis. 

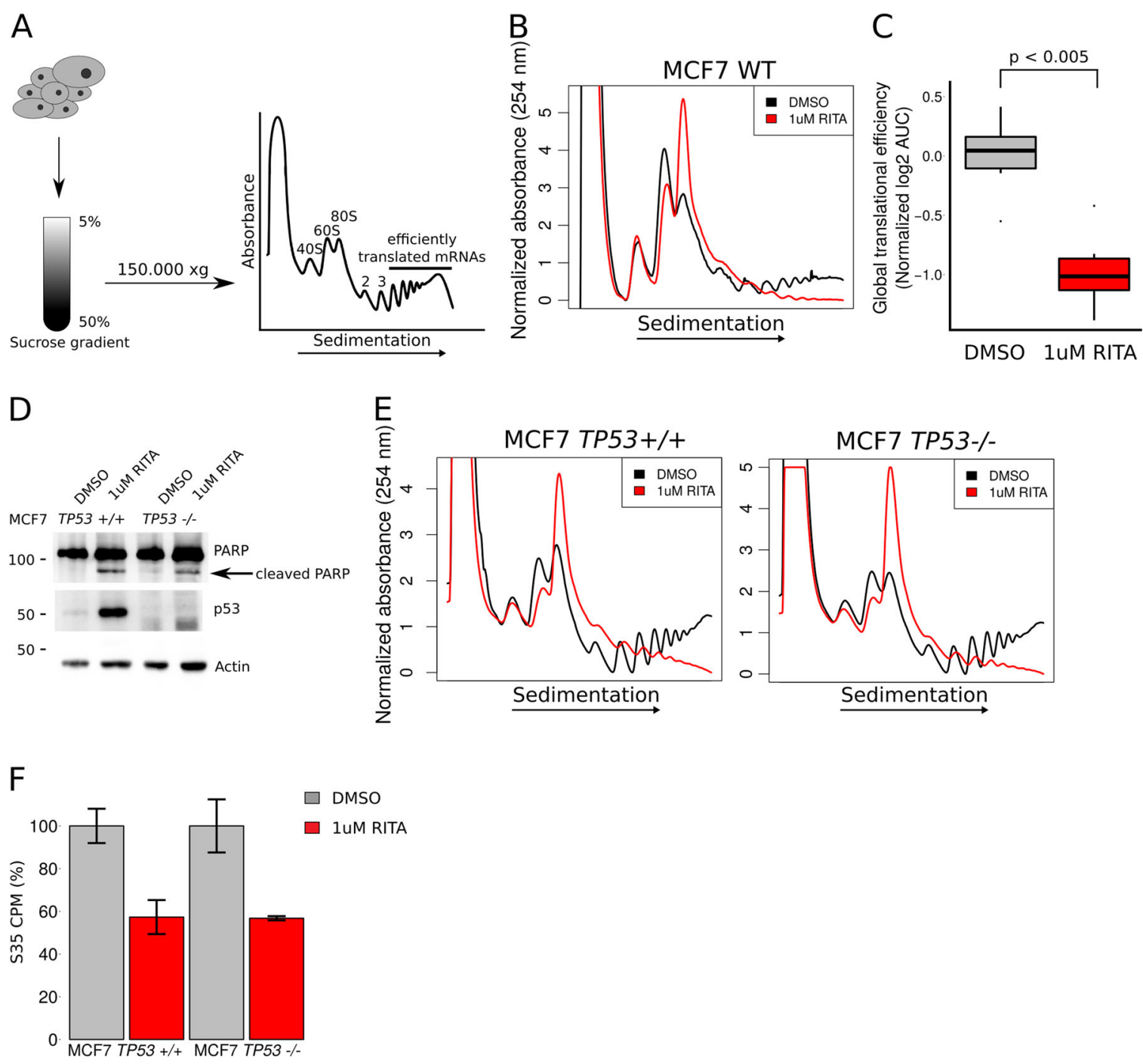

Fig. 1 RITA induces PARP cleavage and represses translation in a TP53- independent manner. a A schematic overview of the polysomeprofiling procedure. During polysome-profiling, cytosolic cell lysates are sedimented on a sucrose gradient and relative amount of ribosomes engaged in efficient translation (i.e., >3 ribosomes on an mRNA) can be quantified by calculating the area under the curve (AUC). b Representative polysome-tracings of MCF7 WT cells treated with vehicle (DMSO) or $1 \mu$ M RITA for $8 \mathrm{~h}$. c Quantification of changes in amounts of efficiently translated mRNA using polysome-tracings from MCF7 WT cells treated with vehicle (DMSO) or $1 \mu \mathrm{M}$ RITA for $8 \mathrm{~h}$ (normalized to mean of vehicle treated cells; $n=6$ ). $\mathbf{d}$ Western blotting of indicated proteins in extracts from MCF7 TP53+/+ and TP53-/- cells treated with vehicle (DMSO) or $1 \mu M$ RITA for $8 \mathrm{~h}$. e Representative polysome-tracings of MCF7 TP53+/ + and TP53-/- cells treated with vehicle (DMSO) or $1 \mu \mathrm{M}$ RITA for $8 \mathrm{~h}$. f Quantification of ${ }^{35} \mathrm{~S}$ labeled nascent proteins in MCF7 TP53+/+ and TP53-/- cells treated with vehicle (DMSO) or $1 \mu \mathrm{M}$ RITA for $8 \mathrm{~h}$ (normalized to mean of vehicle treated MCF7 TP53+/+ or TP53-/- cells; $n=3$, bars represent the mean +/-SD)

\section{RITA suppresses translation by inducing phosphorylation of elF2a}

Another key step modulating translation initiation is recycling of the TC. Therefore, we next assessed whether the effects of RITA on mRNA translation involve changes in phosphorylation of eIF $2 \alpha$. Indeed, $1 \mu \mathrm{M}$ RITA treatment was associated with a time-dependent increase in phosphorylation of eIF2 $\alpha$ in MCF7 WT cells (Fig. 3a). The effect of RITA on eIF2 $\alpha$ phosphorylation was not limited to MCF7 cells as phosphorylation of eIF2 $\alpha$ was also induced in the colon cancer cell lines HCT116 TP53+/+ and GP5d, which express wild-type p53 (Fig. 3b). In addition to full length p53, whose exon 4 was targeted by CRISPR/Cas9 in MCF7 TP53-/- cells, TP53 is also transcribed as a shorter isoform (encoding for both D133p53 and D160p53 protein isoforms; Fig. S2A) which does not include exon $4^{40}$. As these shorter isoforms of p53 are implicated in tumorigenesis and response to DNA damage $^{41,42}$, we assessed whether effects from RITA on eIF2 $\alpha$ phosphorylation and PARP cleavage depend on 

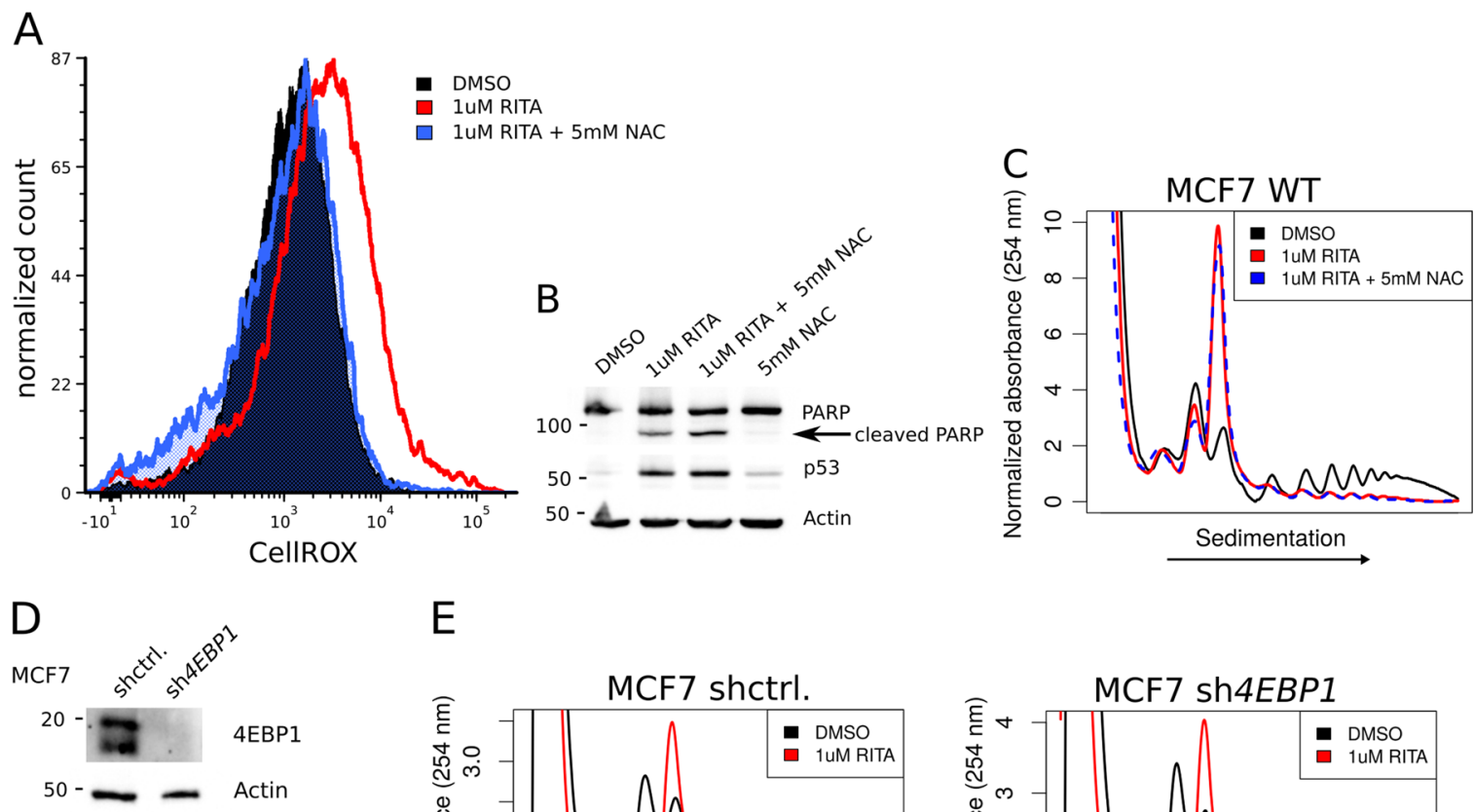

E
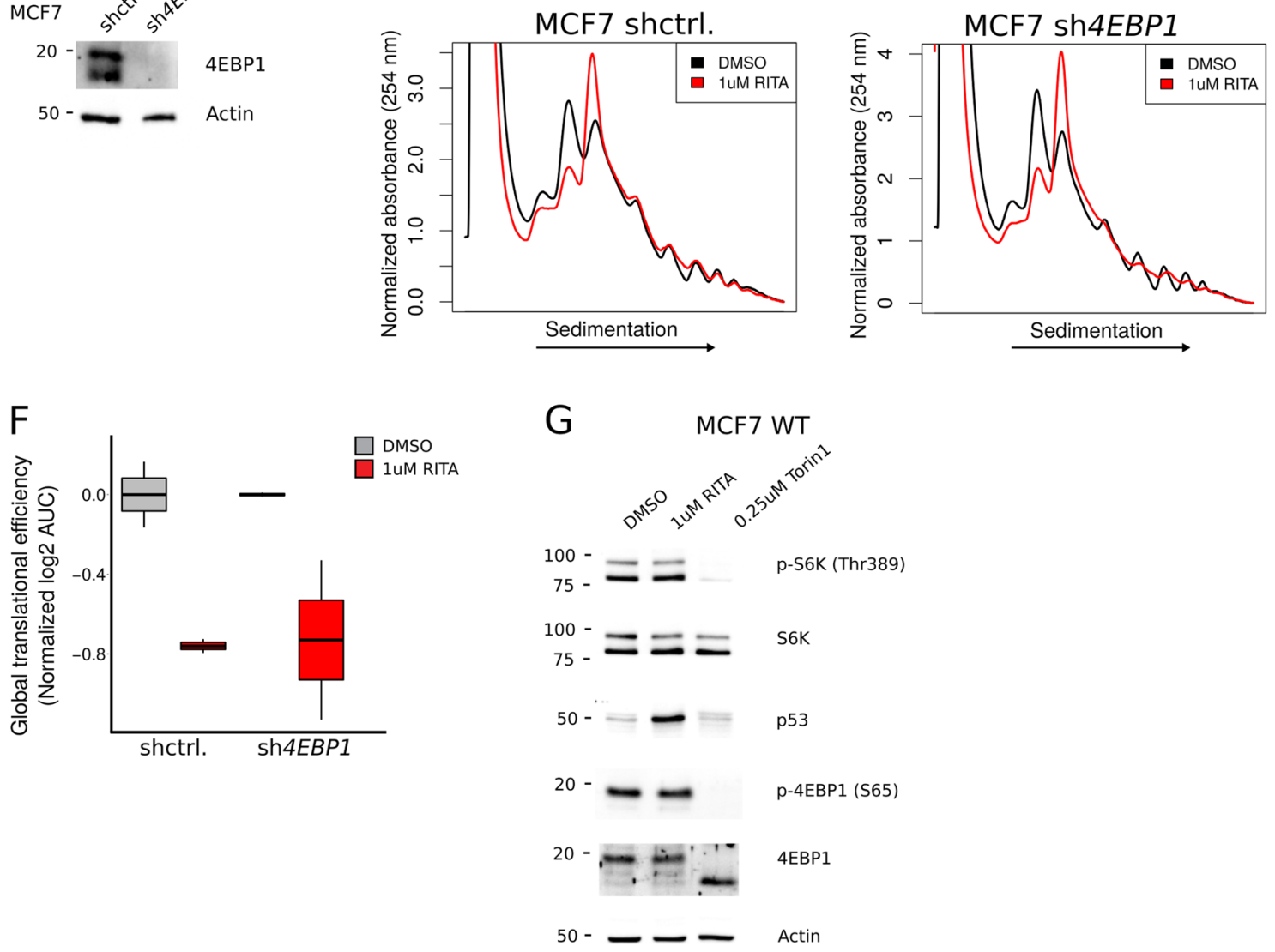

Fig. 2 Suppression of translation following RITA treatment does not depend on ROS accumulation or inhibition of the mTOR/4E-BP axis. a FACS for CellROX Deep Red dye (to quantify ROS) following an $8 \mathrm{~h}$ treatment of MCF7 WT cells with vehicle (DMSO) or $1 \mu \mathrm{m}$ RITA in presence or absence of $5 \mathrm{mM} \mathrm{N}$-Acetyl Cysteine (NAC). b Western blotting for indicated proteins using extracts from MCF7 WT cells treated with vehicle (DMSO) or $1 \mu \mathrm{m}$ RITA in presence or absence of $5 \mathrm{mM}$ NAC. c Polysome-tracings of MCF7 WT cells treated with vehicle (DMSO) or $1 \mu \mathrm{M}$ RITA in presence or absence of $5 \mathrm{mM} \mathrm{NAC}$ for $8 \mathrm{~h}$. $\mathbf{d}$ Western blotting of indicated proteins using extracts from sh-control and sh4EBP1 MCF7 cells. e Representative polysome tracings of sh-control. and sh4EBP1 MCF7 cells treated with vehicle (DMSO) or $1 \mu \mathrm{M}$ RITA for $8 \mathrm{~h}$. $\mathbf{f}$ Quantification of amount of efficiently translated mRNA from polysome-tracings normalized to the mean of vehicle (DMSO) treated sh-control MCF7 cells $(n=2)$. $\mathbf{g}$ Western blot for indicated proteins using extracts from MCF7 WT cells treated with vehicle (DMSO), $1 \mu \mathrm{M}$ RITA or $0.25 \mu \mathrm{M}$ Torin 1 for $8 \mathrm{~h}$ 

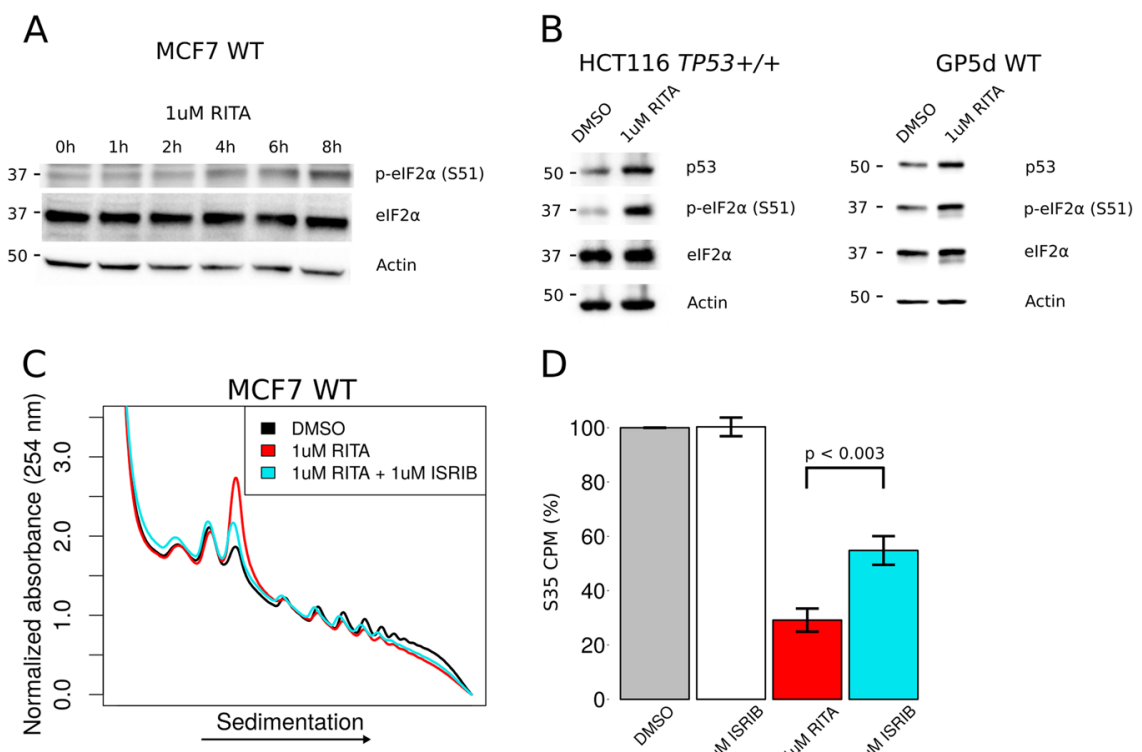

$\mathrm{D}$

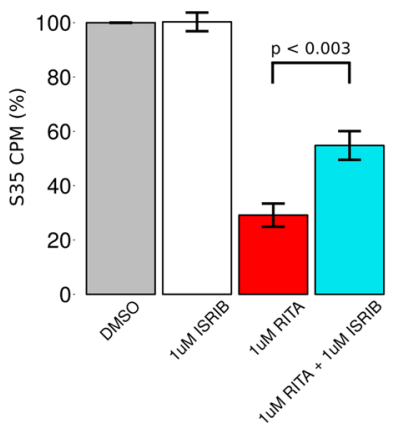

Fig. 3 RITA suppresses translation by inducing phosphorylation of elF2a. a Western blot analysis for indicated proteins using extracts from MCF7 WT cells treated with $1 \mu \mathrm{M}$ RITA for 1-8 h. b Western blot analysis for indicated proteins using extracts from HCT116 TP53+/+ or GP5d WT cells treated with vehicle (DMSO) or $1 \mu \mathrm{M}$ RITA for $4 \mathrm{~h}$. c Polysome profiles of MCF7 WT cells treated with vehicle (DMSO) or $1 \mu \mathrm{M}$ RITA in presence or absence of $1 \mu \mathrm{M}$ ISRIB for $4 \mathrm{~h}$. d Quantification of S35 labeled nascent peptides from MCF7 WT cells following treatment with vehicle (DMSO) or $1 \mu \mathrm{M}$ RITA in presence or absence of $1 \mu \mathrm{M}$ ISRIB for $4 \mathrm{~h}$. Counts per minute (CPM) were normalized to the mean of the vehicle treated cells $(n=3$, bars represent the mean $+/-\mathrm{SD}$ )

D133p53 and D160p53. To this end we transduced MCF7 TP53-/- cells with an shRNA targeting exon 7, which resulted in an approximate fourfold reduction in the mRNA encoding D133p53 and D160p53 as measured by qPCR (MCF7 TP53-/- shD133/D160p53 cells; Fig S2A, $B)$. Indeed, PARP was cleaved and eIF $2 \alpha$ phosphorylated following RITA treatment in MCF7 TP53-/- shD133/ D160p53 cells, which is consistent with RITA-associated anti-cancer effects also independent of D133/D160p53.

To evaluate whether phosphorylation of eIF $2 \alpha$ is necessary for suppression of translation by RITA, we employed the integrated stress response inhibitor $(\text { ISRIB })^{43}$. ISRIB induces eIF2B GEF activity and TC recycling in spite of eIF2 $\alpha$ being phosphorylated ${ }^{44}$. Indeed, ISRIB partially restored translation following RITA treatment as judged by a decrease in the monosome (80S) peak in polysome-tracings (Fig. 3c) and a concomitant increase in ${ }^{\left[{ }^{35]}\right.} \mathrm{S}$-methionine incorporation into nascent peptides (Fig. 3d). Thus, the effects of RITA on translation appear to be mediated by eIF2 $\alpha$ phosphorylation.

\section{RITA-mediated suppression of mRNA translation requires PERK activity}

As discussed above, eIF2 $\alpha$ can be phosphorylated by four kinases, each activated by distinct cellular stresses (reviewed in ref. ${ }^{45}$ ). Among these, PERK is activated via phosphorylation upon ER stress ${ }^{23}$ and multiple reports have indicated a potential role for ER stress during apoptosisinduction following reactivation of $\mathrm{p} 53^{46,47}$. This highlighted the possibility that suppression of protein synthesis following RITA treatment may depend on PERK. Indeed, PERK inhibition using GSK2606414 ${ }^{48}$ reduced RITAinduced eIF2 $\alpha$ phosphorylation (Fig. 4a). This associated with a partial rescue of translation in RITA-treated cells, as judged by a re-distribution of ribosomes from monosomes to polysomes (Fig. 4b, c), together with a reduction in PARP cleavage in MCF7 and GP5d cells (Fig. 4d). Moreover, under PERK inhibition, p53 was no longer induced by RITA (Fig. 4d). Nevertheless, consistent with TP53-independent effects on mRNA translation and PARP cleavage (Fig. 1b-d, Fig. S2), cell viability was restored in a TP53-independent manner when RITA was used in combination with the PERK inhibitor GSK2606414 (Fig. 4e). Moreover, consistent with ROS independent effects of RITA on mRNA translation and PARP cleavage (Fig. 2b, c), GSK2606414 increased rather than reduced levels of ROS following RITA treatment (Fig. 4f).

\section{elF2a phosphorylation status determines the efficacy of RITA}

These results suggest that eIF $2 \alpha$ phosphorylation and subsequent suppression of mRNA translation are 

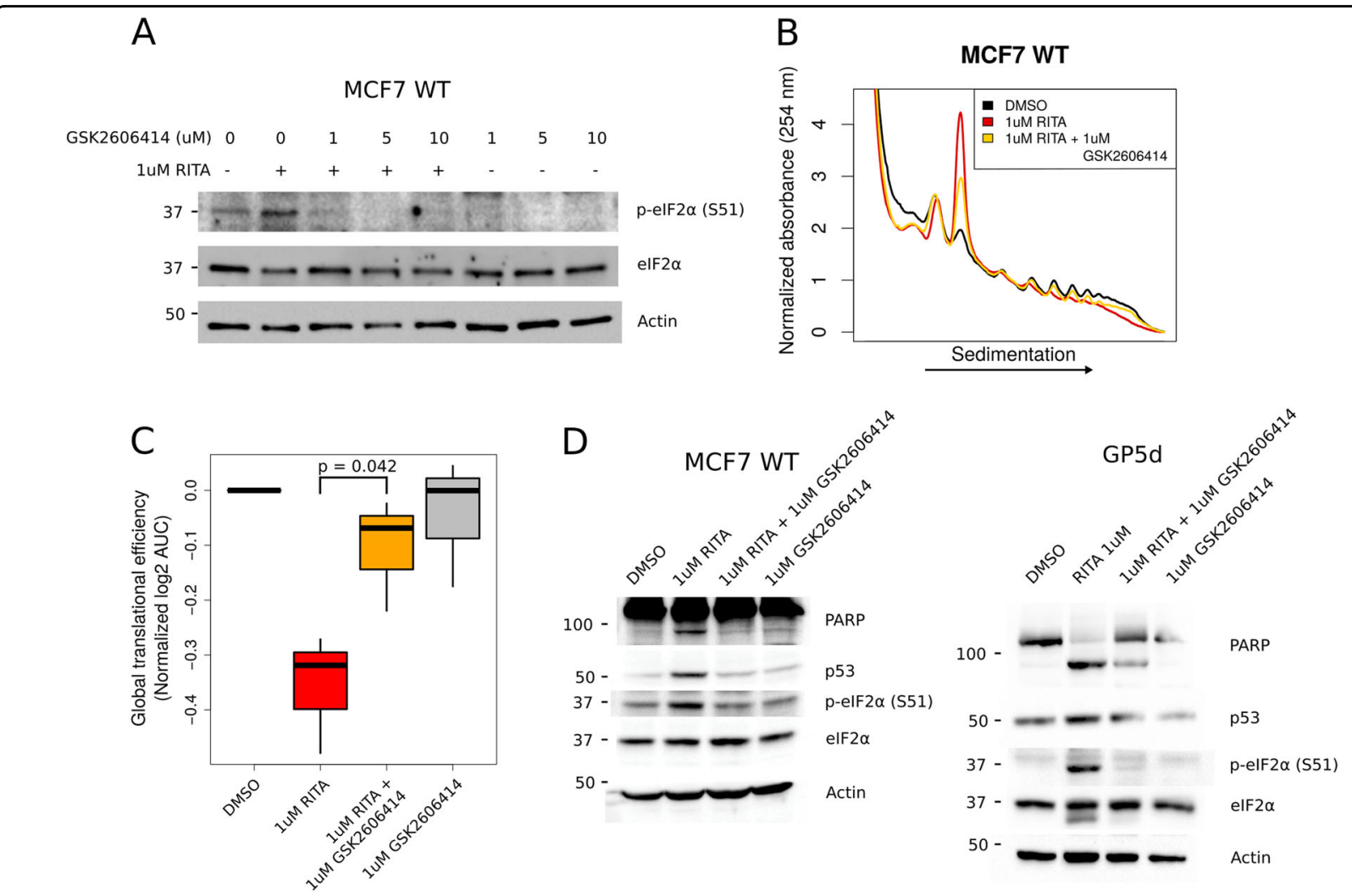

$\mathrm{E}$

F
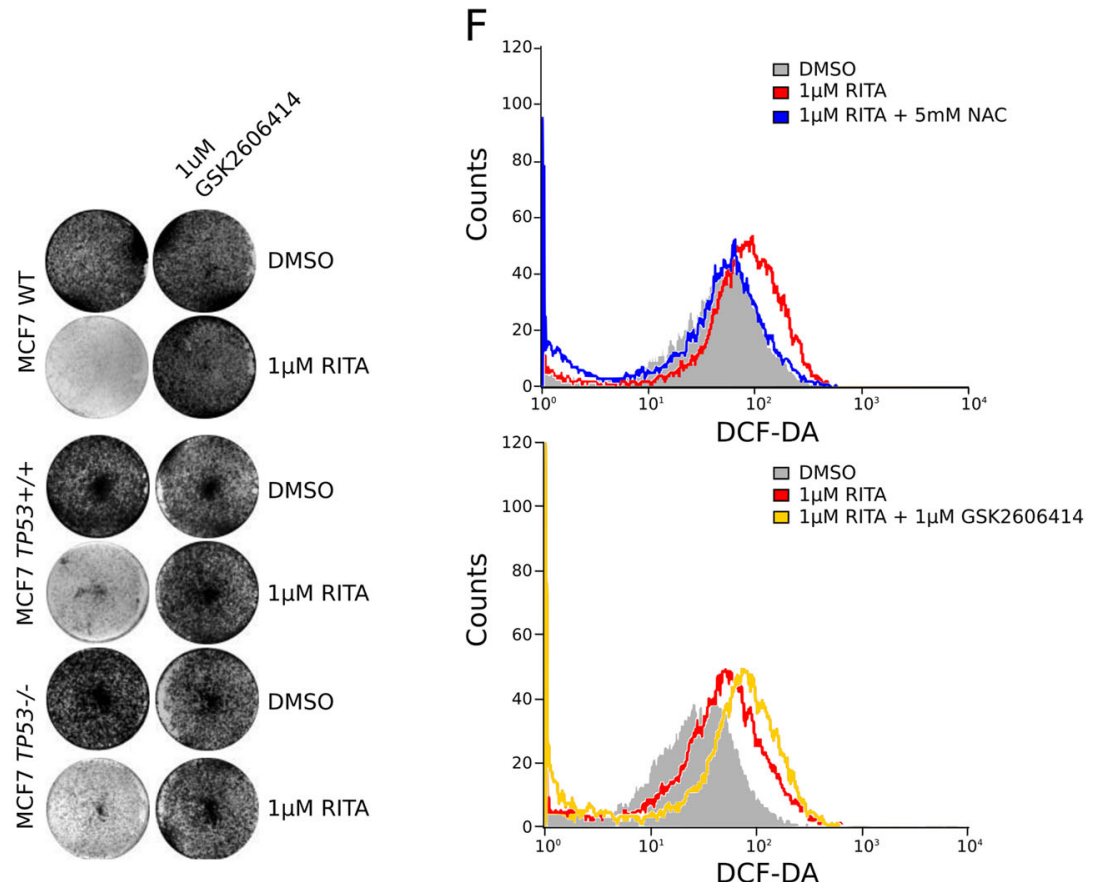

Fig. 4 RITA-mediated suppression of mRNA translation requires PERK activity. a Western Blot analysis using extracts from MCF7 WT cells treated with vehicle (DMSO) or $1 \mu \mathrm{m}$ RITA under increasing concentrations of GSK2606414 for $4 \mathrm{~h}$. $\mathbf{b}$ Representative polysome-tracings of MCF7 WT cells treated with vehicle (DMSO) or $1 \mu \mathrm{M}$ RITA in presence of absence of $1 \mu \mathrm{M}$ GSK2606414 for $4 \mathrm{~h}$. c Quantification of amount of efficiently translated mRNA from polysome-tracings normalized to the mean of vehicle treated MCF7 WT cells. $(n=3$, paired $t$-test between RITA and RITA + GSK2606414) d) Western blotting using extracts from MCF7 WT and GP5d cells treated with vehicle (DMSO) or $1 \mu M$ RITA in presence or absence of $1 \mu \mathrm{M}$ GSK2606414. e Crystal violet staining of MCF7 WT, TP53+/+ and TP53-/- cells treated with vehicle (DMSO) or $1 \mu \mathrm{M}$ RITA in presence or absence of $1 \mu \mathrm{M}$ GSK2606414 for $8 \mathrm{~h}$. f FACS for DCF-DA (to quantify ROS) in MCF7 WT cells treated with vehicle (DMSO) or $1 \mu \mathrm{M}$ RITA in presence or absence of 5 mM NAC (upper) or $1 \mu$ M GSK2606414 (lower) for $8 \mathrm{~h}$ 
A

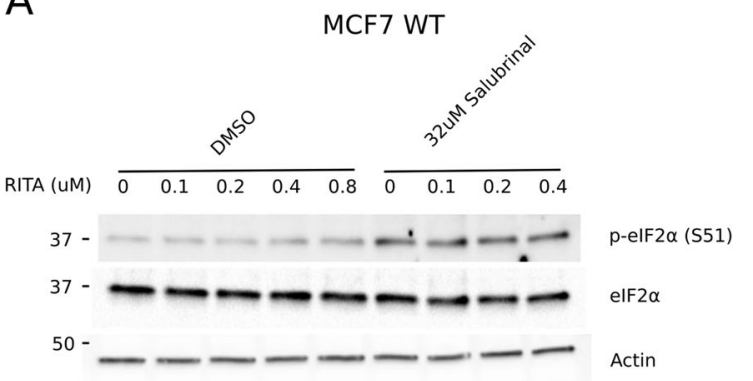

B

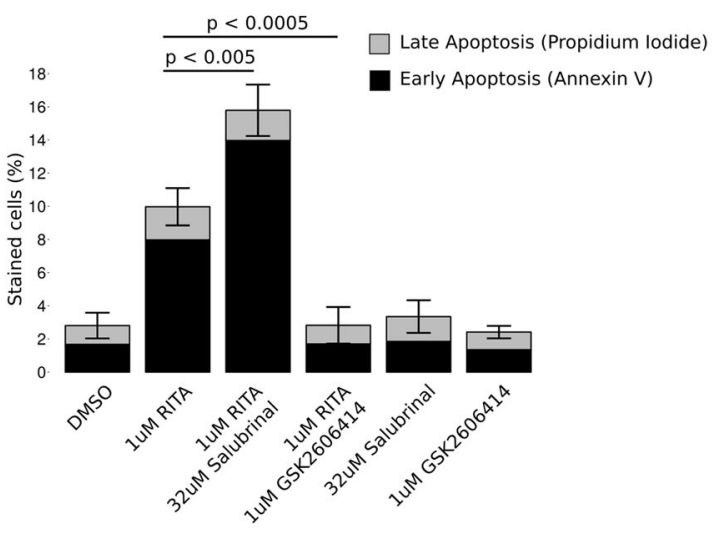

C

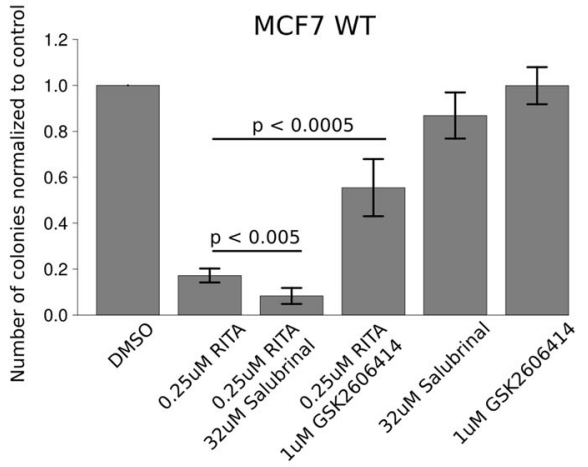

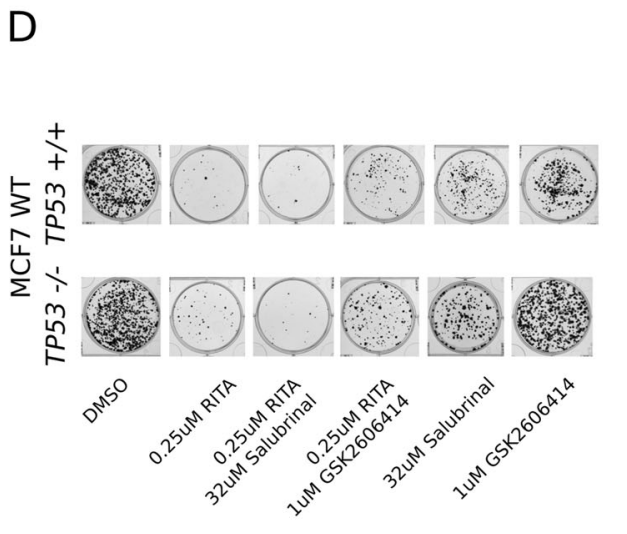

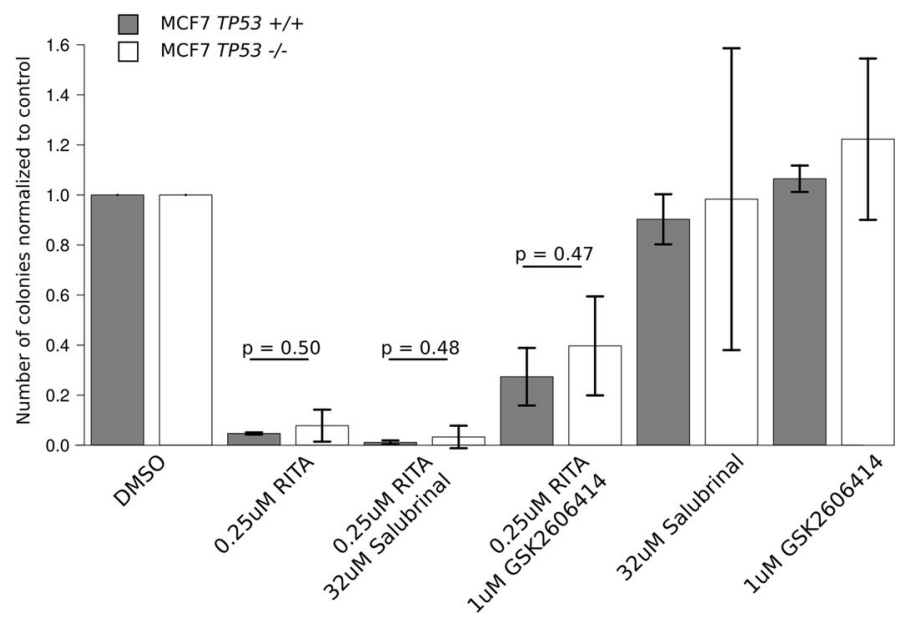

Fig. 5 Phosphorylation of elF2a modulates RITA's effect on apoptosis and colony formation. a Western blot analysis using extracts from MCF7 WT cells treated with increasing concentrations of RITA in presence or absence of $32 \mu \mathrm{M}$ salubrinal for $4 \mathrm{~h}$. $\mathbf{b}$ FACS based quantification of Annexin V and propidium iodide staining to detect early and late apoptosis in MCF7 WT cells treated with vehicle (DMSO) or $1 \mu M$ RITA in presence or absence of $32 \mu \mathrm{M}$ salubrinal or $1 \mu \mathrm{M}$ GSK2606414 for $4 \mathrm{~h}(n=3)$. c, d Crystal violet staining of WT (c), TP53+/+ or TP53-/- MCF7 cells (d) after treatment with vehicle (DMSO) or $1 \mu \mathrm{M}$ RITA in presence or absence of $32 \mu \mathrm{M}$ salubrinal or $1 \mu \mathrm{M}$ GSK2606414 ( $4 \mathrm{~h}$ treatment followed by a 10 day expansion before staining). The pictures represent representative images and quantification was performed on $n=3$ experiments. All bars represent the mean $+/-$ SD

correlated with the pro-apoptotic effects of RITA. To explore the causality of this relationship, we suppressed or stimulated eIF2 $\alpha$ phosphorylation using the PERK inhibitor GSK2606414 $4^{48}$ or salubrinal, which inhibits eIF2 $\alpha$ phosphatases and thereby enhances phosphorylation of eIF2 $\alpha$ [ref. ${ }^{49}$, Fig. 5a], respectively. GSK2606414 $(1 \mu \mathrm{M})$ reversed induction of apoptosis induced by RITA $(1 \mu \mathrm{M})$ (Fig. 5b) as assessed by Annexin V/propidium iodide (PI) 

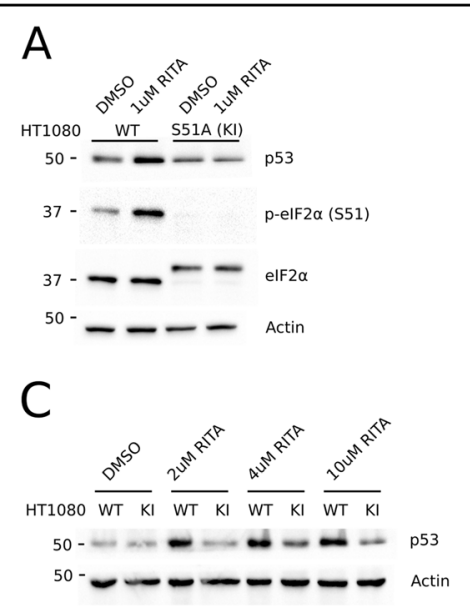

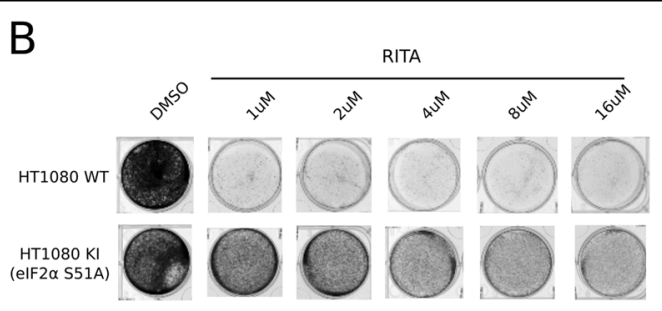

D

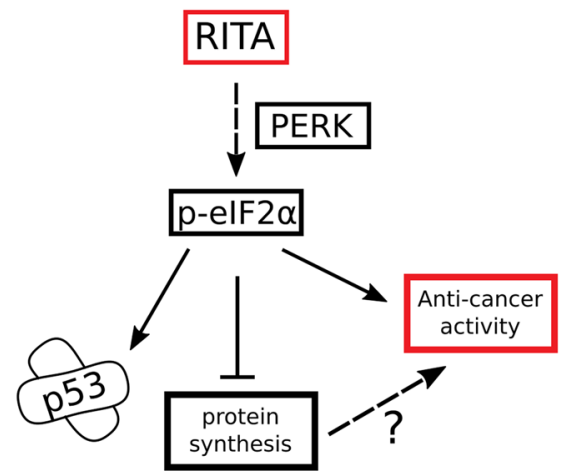

Fig. 6 RITA's effects on clonogenicity and p53 activation depend on phosphorylation of elF2alpha. a Western blot analysis of indicated proteins using extracts from HT1080 WT and HT1080 KI (elF2aS51A) cells treated with vehicle (DMSO) or $1 \mu$ M RITA for 8 h. b Crystal violet staining of HT1080 WT and HT1080 KI cells treated with increasing concentrations of RITA. c Western blot analysis of indicated proteins using extracts from HT1080 WT and Kl cells treated with vehicle (DMSO) or increasing concentrations of RITA for $8 \mathrm{~h}$. $\mathbf{d}$ Schematic of RITA's p-elF2a dependent effects on p53 reactivation, protein synthesis and anti-cancer activity

staining. Conversely, treatment with $32 \mu \mathrm{M}$ salubrinal in combination with $1 \mu \mathrm{M}$ RITA potentiated induction of apoptosis as compared to RITA alone (Fig. 5b). Moreover, salubrinal $(32 \mu \mathrm{M})$ potentiated inhibitory effects of RITA $(1 \mu \mathrm{M})$ on colony formation in MCF7 cells, while GSK26064141 (1 $\mu \mathrm{M})$ caused the opposite effect (Fig. 5c). Consistent with a TP53-independent effect on mRNA translation and PARP cleavage (Fig. 1d-f), TP53 status did not exert a major effect on colony formation in MCF7 cells across the treatments (Fig. 5d).

To further establish the relationship between the antineoplastic effects of RITA and eIF $2 \alpha$ phosphorylation, we employed the wild-type TP53 lung fibrosarcoma cell line HT1080 expressing either wild-type (HT1080 WT) or a non-phosphorylatable eIF2 $\alpha$ mutant (serine 51 to alanine mutation; HT1080 KI) ${ }^{50}$ (Fig. 6a). Strikingly, the inability of HT1080 KI cells to phosphorylate eIF2 $\alpha$ was associated with increased cell viability under a range of RITA concentrations $(1-16 \mu \mathrm{M})$ (Fig. 6b). Moreover, RITA-induced p53 in HT1080 WT, but not KI cells (Fig. 6c). This is consistent with the attenuation of p53 induction by RITA under conditions wherein eIF2 $\alpha$ phosphorylation is reduced by PERK inhibition (Fig. 4d). Collectively, these findings support a model whereby induction of p53 by RITA depends on phosphorylation of eIF2 $\alpha$ (Fig. 6d).

\section{Discussion}

RITA has been demonstrated to prevent proteasomal degradation of p53 by inhibiting the p53-MDM2 interaction $^{51}$. However, as shown here and previously in HCT116 cells ${ }^{17}$, RITA appears to exert its antineoplastic effects independently of TP53. Interestingly, several p53 reactivating drugs elicit effects that are independent or only partially dependent on the presence of p53. For example PRIMA-1Met, which reactivates mutant p53, currently in phase I/II clinical trials, has been shown to reduce phosphorylation of MEK, independently of TP53, and thereby impair anchorage-independent growth ${ }^{14}$. Moreover, PRIMA-1Met disrupts the GSH/ROS balance and induces autophagy and apoptosis irrespective of TP53 status ${ }^{15,52}$. Similarly, in multiple myeloma, PRIMA-1Met induces ER stress through p73 demethylation and cells without TP53 showed the highest drug sensitivity ${ }^{19}$. Finally, p53 was shown to be dispensable for a decrease in clonogenic potential of several cell lines following RITA treatment, which instead correlated with the induction of DNA damage ${ }^{53}$. Strikingly, many of these TP53-independent effects impinge on the eIF2 $\alpha$-dependent regulation of mRNA translation [ref. ${ }^{36}$ and reviewed in ref. ${ }^{54}$ ]. Consistently, RITA dramatically induced eIF $2 \alpha$ phosphorylation, whereby phospho-eIF $2 \alpha$ appears to be a critical mediator of the proapoptotic and antineoplastic 
effects of RITA independently of p53 including its isoforms D133p53 and D160p53. This is in accordance with a recent study showing an increased radio-sensitivity of cervical cancer cell lines in the presence of RITA, which required induction of ER-stress but occurred independently of $T P 53^{55}$.

Preventing phosphorylation of eIF2 $\alpha$ via PERK inhibition alleviated the pro-apoptotic effects of RITA and partially restored the ability of unlimited cell-division independently of TP53. This supports the tenet that PERK, although essentially pro-survival, can also promote apoptotic cell death in a context dependent fashion ${ }^{56}$. Moreover, it has been shown that the persistent activation of PERK in the absence of IRE1 and ATF6 activity during prolonged ER stress represents a terminal pro-apoptotic stage of the unfolded protein response ${ }^{57}$. Accordingly, augmenting the induction of eIF $2 \alpha$ phosphorylation by RITA using salubrinal resulted in more potent proapoptotic and antineoplastic effects relative to using RITA alone. A similar effect may account for the improved activity of RITA in increasing radio-sensitivity of cervical cancer cell lines treated with RITA ${ }^{55}$.

Overall, we provide evidence that RITA selectively induces PERK activity thereby effectively suppressing mRNA translation and inducing apoptosis in a TP53independent manner. Moreover, these results point to the importance of the stress sensing eIF2 $\alpha$ pathway in deciding the cellular fate in the context of RITA, and possibly other p53 reactivating agents, and show that modulation of this pathway may be exploited for therapeutic purposes.

\section{Acknowledgements}

This research was supported by grants from the Swedish Research Council, The Swedish Cancer Society, The Stockholm Cancer Society, STRATCAN and the Knut and Alice Wallenberg Foundation (all to O.L.) and R01 DK053307 by the $\mathrm{NIH}$ to M.H. I.T. is a scholar of the Fonds de Recherche du Québec-Santé (FRQS; Junior 2).

\section{Author details}

'Department of Onkology-Pathology, Science for Life Laboratories, Karolinska Institutet, Stockholm, Sweden. ${ }^{2}$ Department of Microbiology, Tumor and Cell Biology, Karolinska Institutet, Stockholm, Sweden. ${ }^{3}$ Department of Genetics and Genome Sciences, Case Western Reserve University, Cleveland, OH, USA. ${ }^{4}$ Lady Davis Institute, SMBD JGH and Gerald Bronfman Department of Oncology, McGill University, Montreal, QC, Canada

\section{Conflict of interest}

The authors declare that they have no conflict of interest.

\section{Publisher's note}

Springer Nature remains neutral with regard to jurisdictional claims in published maps and institutional affiliations.

Supplementary Information accompanies this paper at (https://doi.org/ 10.1038/s41419-019-2074-3).

Received: 25 April 2019 Revised: 30 September 2019 Accepted: 15 October 2019
Published online: 07 November 2019

\section{References}

1. Horn, H. \& Vousden, K. Coping with stress: multiple ways to activate p53. Oncogene 26, 1306-1316 (2007).

2. Lazo, P. A. Reverting p53 activation after recovery of cellular stress to resume with cell cycle progression. Cell. Signal. 33, 49-58 (2017).

3. Bieging, K. T., Mello, S. S. \& Attardi, L. D. Unravelling mechanisms of p53mediated tumour suppression. Nat. Rev. Cancer 14, 359-370 (2014).

4. Joerger, A. C. \& Fersht, A. R. The p53 pathway: origins, inactivation in cancer, and emerging therapeutic approaches. Annu. Rev. Biochem. 85, 375-404 (2016).

5. Kandoth, C. et al. Mutational landscape and significance across 12 major cancer types. Nature 502, 333-339 (2013).

6. Momand, J., Zambetti, G. P., Olson, D. C., George, D. \& Levine', A. J. The mdm-2 oncogene product forms a complex with the p53 protein and inhibits p53mediated transactivation. Cell 69, 1237-1245 (1992).

7. Linares, L. K., Hengstermann, A., Ciechanover, A., Müller, S. \& Scheffner, M. HdmX stimulates Hdm2-mediated ubiquitination and degradation of p53. Proc. Natl Acad. Sci. USA 100, 12009-12014 (2003).

8. Zawacka-Pankau, J. \& Selivanova, G. Pharmacological reactivation of p53 as a strategy to treat cancer. J. Intern. Med. 277, 248-259 (2015).

9. Bykov, V. J. N. et al. Restoration of the tumor suppressor function to mutant p53 by a low-molecular-weight compound. Nat. Med. 8, 282-288 (2002).

10. Issaeva, N. et al. Small molecule RITA binds to p53, blocks p53-HDM-2 interaction and activates p53 function in tumors. Nat. Med. 10, 1321-1328 (2004).

11. Vassilev, L. T. et al. In vivo activation of the p53 pathway by small-molecule antagonists of MDM2. Science 303, 844-848 (2004).

12. Wang, S. et al. SAR405838: an optimized inhibitor of MDM2-p53 interaction that induces complete and durable tumor regression. Cancer Res. 74, 5855-5865 (2014).

13. Lehmann, S. et al. Targeting p53 in vivo: a first-in-human study with p53targeting compound APR-246 in refractory hematologic malignancies and prostate cancer. J. Clin. Oncol. 30, 3633-3639 (2012).

14. Lu, T. et al. PRIMA-1Met suppresses colorectal cancer independent of $p 53$ by targeting MEK. Oncotarget 7, 83017-83030 (2016).

15. Tessoulin, B. et al. PRIMA-1Met induces myeloma cell death independent of p53 by impairing the GSH/ROS balance. Blood 124, 1626-1636 (2014).

16. Weilbacher, A., Gutekunst, M., Oren, M., Aulitzky, W. E. \& van der Kuip, H. RITA can induce cell death in p53-defective cells independently of p53 function via activation of JNK/SAPK and p38. Cell Death Dis. 5, e1318 (2014).

17. Wanzel, M. et al. CRISPR-Cas9-based target validation for p53-reactivating model compounds. Nat. Chem. Biol. 12, 22-28 (2016).

18. Valentine, J. M., Kumar, S. \& Moumen, A. A p53-independent role for the MDM2 antagonist Nutlin-3 in DNA damage response initiation. BMC Cancer 11, 79 (2011).

19. Teoh, P. J. et al. PRIMA-1 targets the vulnerability of multiple myeloma of deregulated protein homeostasis through the perturbation of ER stress via p73 demethylation. Oncotarget 7, 61806-61819 (2016).

20. Wek, R. C., Jiang, H.-Y. \& Anthony, T. G. Coping with stress: elF2 kinases and translational control. Biochemical Soc. Trans. 34, 7-11 (2006).

21. Hinnebusch, A. G. The scanning mechanism of eukaryotic translation initiation. Annu. Rev. Biochem. 83, 779-812 (2014).

22. Sonenberg, N. \& Hinnebusch, A. G. Regulation of translation initiation in eukaryotes: mechanisms and biological targets. Cell 136, 731-745 (2009).

23. Harding, H. P., Zhang, Y. \& Ron, D. Protein translation and folding are coupled by an endoplasmic-reticulum-resident kinase. Nature 397, 271-274 (1999).

24. Vattem, K. M., Staschke, K. A. \& Wek, R. C. Mechanism of activation of the double-stranded-RNA-dependent protein kinase, PKR Role of dimerization and cellular localization in the stimulation of PKR phosphorylation of eukaryotic initiation factor-2 (elF2). Eur. J. Biochem. 268, 3674-3684 (2001).

25. Chen, J.J. \& London, I. M. Regulation of protein synthesis by heme-regulated elF-2a kinase. Trends Biochemical Sci. 20, 105-108 (1995).

26. Hinnebusch, A. G. Translational regulation of GCN4 and the general amino acid control of yeast. Annu. Rev. Microbiol. 59, 407-450 (2005).

27. Choy, M. S. et al. Structural and functional analysis of the GADD34:PP1 elF2a phosphatase. Cell Rep. 11, 1885-1891 (2015).

28. Guan, B.J. et al. A unique ISR program determines cellular responses to chronic stress. Mol. Cell 68, 885-900.e6 (2017). 
29. Nishitoh, H. CHOP is a multifunctional transcription factor in the ER stress response. J. Biochem. 151, 217-219 (2012).

30. Krajewski, M., Ozdowy, P., D'Silva, L., Rothweiler, U. \& Holak, T. A. NMR indicates that the small molecule RITA does not block p53-MDM2 binding in vitro. Nat. Med. 11, 1135-1136 (2005). author reply 1136-1137.

31. Cong, L. et al. Multiplex genome engineering using CRISPR/Cas systems. Science 339, 819-823 (2013).

32. Gandin, V. et al. Polysome fractionation and analysis of mammalian translatomes on a genome-wide scale video link. J. Vis. Exp. 87, 514553791-51455 (2014).

33. Zaccara, S. et al. p53-directed translational control can shape and expand the universe of p53 target genes. Cell Death Differ. 21, 1522-1534 (2014).

34. Lindqvist, L. M. et al. Translation inhibitors induce cell death by multiple mechanisms and $\mathrm{Mcl}-1$ reduction is only a minor contributor. Cell Death Dis. $\mathbf{3}$, e409-e409 (2012)

35. Shi, Y. et al. ROS-dependent activation of JNK converts p53 into an efficient inhibitor of oncogenes leading to robust apoptosis. Cell Death Differ. 21 612-623 (2014).

36. Shenton, D. et al. Global translational responses to oxidative stress impact upon multiple levels of protein synthesis. J. Biol. Chem. 281, 29011-29021 (2006).

37. Saxton, R. A. \& Sabatini, D. M. mTOR signaling in growth, metabolism, and disease. Cell 168, 960-976 (2017).

38. Roux, P. P. \& Topisirovic, I. Signaling pathways involved in the regulation of mRNA translation. Mol. Cell. Biol. 38, e00070-18- (2018).

39. Thoreen, C. C. et al. An ATP-competitive mammalian target of rapamycin inhibitor reveals rapamycin-resistant functions of mTORC1. J. Biol. Chem. 284 8023-8032 (2009).

40. Khoury, M. P. \& Bourdon, J.-C. p53 isoforms: an intracellular microprocessor? Genes Cancer 2, 453-465 (2011).

41. Aoubala, M. et al. p53 directly transactivates $\triangle 133 \mathrm{p} 53 \mathrm{a}$, regulating cell fate outcome in response to DNA damage. Cell Death Differ. 18, 248-258 (2011).

42. Candeias, M. M., Hagiwara, M. \& Matsuda, M. Cancer-specific mutations in p53 induce the translation of $\triangle 160 \mathrm{p} 53$ promoting tumorigenesis. EMBO Rep. 17 1542-1551 (2016).

43. Sidrauski, C., Mcgeachy, A. M., Ingolia, N. T. \& Walter, P. The small molecule ISRIB reverses the effects of elF2 a phosphorylation on translation and stress granule assembly. 1-16. https://doi.org/10.7554/eLife.05033. (2015)
44. Zyryanova, A. F. et al. Binding of ISRIB reveals a regulatory site in the nucleotide exchange factor elF2B. Science 359, 1533-1536 (2018).

45. Donnelly, N., Gorman, A. M., Gupta, S. \& Samali, A. The elF2a kinases: thei structures and functions. Cell. Mol. Life Sci. 70, 3493-3511 (2013).

46. Lin, W.-C. et al. Endoplasmic reticulum stress stimulates p53 expression through NF-kB activation. PLoS ONE 7, e39120 (2012).

47. Qu, L. \& Koromilas, A. E. Control of tumor suppressor p53 function by endoplasmic reticulum stress. Cell Cycle 3, 567-570 (2004).

48. Axten, J. M. et al. Discovery of 7-methyl-5-(1-\{[3-(trifluoromethyl)phenyl] acetyl\}-2,3-dihydro-1 $\mathrm{H}$-indol-5-yl)-7 H -pyrrolo[2,3- d]pyrimidin-4-amine (GSK2606414), a potent and selective first-in-class inhibitor of protein kinase R (PKR)-like endoplasmic reticulum kinase (PERK). J. Med. Chem. 55, 7193-7207 (2012).

49. Boyce, M. et al. A selective inhibitor of elF2alpha dephosphorylation protects cells from ER stress. Science 307, 935-939 (2005).

50. Rajesh, K. et al. elF2a phosphorylation bypasses premature senescence caused by oxidative stress and pro-oxidant antitumor therapies. Aging 5, 884-901 (2013).

51. Issaeva, N. et al. Small molecule RITA binds to p53, blocks p53-HDM-2 interaction and activates p53 function in tumors. Nat. Med. 10, 1321-1328 (2004).

52. Yoshikawa, N. et al. PRIMA-1MET induces apoptosis through accumulation of intracellular reactive oxygen species irrespective of p53 status and chemo-sensitivity in epithelial ovarian cancer cells. Oncol. Rep. 35, 2543-2552 (2016)

53. Ahmed, A., Yang, J., Maya-Mendoza, A., Jackson, D. A. \& Ashcroft, M. Pharmacological activation of a novel p53-dependent S-phase checkpoint involving CHK-1. Cell Death Dis. 2, e160 (2011).

54. Kondrashov, A. V., Spriggs, K. A., Bushell, M. \& Willis, A. E. Co-ordinated regulation of translation following DNA damage. Cell Cycle 8, 3067-3068 (2009).

55. Zhu, $\mathrm{H}$. et al. RITA enhances irradiation-induced apoptosis in p53-defective cervical cancer cells via upregulation of IRE1a/XBP1 signaling. Oncol. Rep. 34, 1279-1288 (2015).

56. Lin, J. H., Li, H., Zhang, Y., Ron, D. \& Walter, P. Divergent effects of PERK and IRE1 signaling on cell viability. PLOS ONE 4, e4170 (2009).

57. Lin, J. H. et al. IRE1 signaling affects cell fate during the unfolded protein response. Science 318, 944-949 (2007). 